\title{
Review
}

\section{Present day medical education in India: Is it serving the purpose?}

\author{
N.S. Dhaniwala*
}

Department of Orthopedics, JN Medical College \& AVBRH, Datta Meghe Institute of Medical Sciences, Sawangi, Wardha 442107, Maharashtra, India

* Corresponding author (E-mail.: nsdhaniwala@gmail.com)

\begin{abstract}
Medical Education in India is passing through multiple modifications. It is considered failing in producing well trained doctors to cater to our health needs. Doctors on the other hand, are facing problems from society, medical schools and due to consumer protection act. The etiology of this situation is multifactorial and requires serious consideration by improvement.
\end{abstract}

Keywords: Medical, Education, Doctors

\section{Introduction}

Medical education in India is presently passing through multiple changes. Medical council of India has implemented competency-based curriculum for Bachelor of Medicine and Surgery (MBBS) course from the current academic year. Post graduate curriculum is also undergoing changes in content and methods of teaching, with specific defined hours of learning and practical training. Inter departmental interaction on the related topics is being revived. The central government of India is in favor of increasing the number of medical colleges to correct the doctor- patient ratio in the country. Besides, it has increased the undergraduate and post graduate seats in different existing medical colleges almost to the possible upper limits. Medical council of India, as the regulatory body for maintaining the standards of medical education focuses on inspection of infrastructure, staff and patient load in the attached hospitals. It finds difficulty in granting permission to many such new colleges and courses. Many new colleges then land in a complex situation after admission of students, putting their future at stake.

The general public opinion these days is becoming anti doctors. A large number of instances against doctors' behavior, treatment policy and exorbitant charges have been publicized in one way or the other. The social media highlights such videos rather frequently. Instances of manhandling of on duty doctors in government and private hospitals are increasing day by day with no permanent solution in sight. The metropolitan cities with its corporate hospitals, have contributed a lot in making the health care costly, unreliable and devoid of humane approach in the doctor patient relationship. Privatization of medical education and autonomy to a large number of medical colleges, seem to be increasing the number of medical graduates and post graduates at the cost of quality of training.

\section{Problem}

The public is unsatisfied about health care system despite wide spread network of health care centers staring from village level to cities. Doctors do not want to serve in the rural areas due to multiple reasons of lack of basic life facilities of education, housing, entertainment and poor social interaction. Doctors feel isolated in compulsory rural service clause due to no fixed policy about posting at the time of willingness to serve or soon after passing the qualifying examinations. Poor training as MBBS trainee is another reason of reluctance to serve in rural areas. Society has become violent and aggressive in nature. Only a doctor is supposed to be available and work with $100 \%$ efficiency like computer, even though paramedical manpower and infrastructural deficiency may exist severely in the work place. The relations feel that life has to be saved irrespective of the delay in approaching the hospital, irrespective of facilities of proper diagnosis \& management there and irrespective of the universal fact that doctor tries but the supreme power decides. Human body does not work like a machine or on the principles of mathematics where $2+2$ will always result in 4 .

Bringing the health care provider under Consumer Protection Act (CPA) has definitely increased the cost of treatment. Law sees medical treatment like a commodity purchased by money. This has turned hospitals into shops and doctors as shop keepers. Service is bought and it is now graded depending on the facilities of stay, entertainment, comfort and quality of shop keeper (doctor). Hospitals are becoming like five-star hotels, thereby charges are skyrocketing naturally. In this comfortable scene of socalled centers of treatment, the main element is not and cannot be expected to be the age old honest, expert taking care of all the ailments of the buyers with $100 \%$ success uniformly. Mishaps have occurred and will happen in future also, despite lacs of rupees being spent on hospital luxuries, investigations and management of the disease and its complications. The interactions in the human body are so complex and silently occurring that diagnosing these in the nick of the time will require some magician's power. This fact is neither understood and rarely explained in clear way by the doctor to the patient $\&$ relation.

Points of good doctor patient relationship are not taught in MBBS or post graduate training. The doctor knows the steps of managing a disease but most of them are ill-trained to tackle the accompanying relations and situations arising in 
emergency death, sudden complications and pre and post treatment counselling to the family members. Practical points of individual or group practice, ethics in medical treatment, necessary paper work, and implementing preventive steps for many diseases are points to be acted upon by every practitioner. Due to sudden increase in the number of doctors graduating every year from Indian medical colleges having inadequate teaching- training facilities, poor clinical exposure and the minimum practical training during internship, an MBBS graduate is ill equipped to face the patients without supervision.

\section{Genesis of the problem}

The problems of medical education have started with the unplanned mushrooming of medical institutions of various categories. Starting a medical institute and awarding innumerable basic and specialization degrees still remain one of the most lucrative business in our country. That is why a college starting on a specific year tries to upgrade to autonomous status soon to have full freedom in decision making related to exams., pattern of passing, fees and related matters. Many famous institutions have a system of awarding marks in the final examination based on the attendance in classes, thus bringing down the importance of learning significantly. Individual universities have variable set of regulations for their affiliated medical schools (Sood, 2008). The entry system to medical schools now is uniform allover the country. Still the pattern of Multiple-Choice Questions (MCQ) tests primarily the memory power. Humanitarian attitude much needed to become a doctor is not evaluated at all (Salim). There is a grave deficiency of skilled and motivated teachers in most of the medical colleges, because they are underpaid and choose teaching profession reluctantly. With permission of practice, teachers also prefer themselves to be called as consultants rather than professors. The society also does not consider a teaching doctor as a physician/surgeon many times, indirectly affecting the pride of teacher.

Rote learning is given more importance than clinical skill, thus making the doctor ill trained. This may be due to inadequate number of patients visiting the attached hospitals, mostly situated in rural setting or due to the large number of students to be trained with skeleton teaching faculty. Assessment methods at various levels also are flawed. Some institutions had a system of uninterrupted passing against monetary considerations. Post MBBS internship training also suffers from lack of supervision and assessment. Most of the time this period is used as a time to study for post graduate entrance examination (Supe and Burdick, 2006). A study regarding the medical education in India, funded by the Bill and Melinda Gates Foundation in 2012 stated that "training in and of itself is not a guarantor of high quality" (Chakrabarty, 2016). Thus, with the basic training as doctor remaining inadequate, very few MBBS graduates opt for medical officer job, so much needed for our rural health care. Most of the students attempt at least one to two times, for entry in a post graduate course, which teaches us more and more of a small subject. The specialization and super-specialization craze have destroyed the BASIC DOCTOR, as envisaged initially in our country for larger health care.

\section{Solution}

A few of the simple steps to improve the medical education scene in our country may be as follows:
1. The selection process for medical entry is now uniform but it gives more importance to memory testing. It may be made partly analytical and should have a section to test humanitarian attitude much needed to become a doctor.

2. More stress needs to be given to small group teaching, tutorial demonstration, practical exercises along with optimum didactic teaching.

3. Clinical teaching needs to be imparted with regularity, with stress on demonstration of physical findings and examination skill. Assessment should also be on models or patients rather than theoretical question answers.

4. Incentive marking for attendance should be stopped, to have due importance to learning of subject content and skill acquisition.

5. Summative single assessment be replaced with at least three formative assessments having all types of questions, so that student learns all aspects of a topic.

6. Internship should be compulsorily assessed in the basic clinical subjects, to check whether the trainee has essential theoretical background \& has acquired the practical skill to practice as a basic doctor.

7. Training of basic management skill, communication skill, record keeping, points of good doctor patient relationship, medical ethics, medico-legal examination, consumer protection act, medical insurance etc. should be taught in clinical training essentially.

8. Medical teachers' vacant posts should be filled on priority with motivated and experienced teachers. Good teachers may be given incentive.

9. The fees pattern of medical courses be made affordable, so that outcoming doctors do not feel the need of over charging to repay huge loans.

10. Instead of opening further new colleges with inadequate facilities, stress may be given to consolidate the condition of the existing medical schools.

\section{Conclusion}

Medical education in India is in a state of chaos, producing ill trained graduates \& post graduates. Health care system of the country suffers due to this. It is necessary to look into its genesis and take remedial steps.

\section{References}

Chakrabarty, R., (2016). Problems plaguing medical education: Why India suffers a severe lack of quality doctors. July 6, 2016 India today web desk (indiatoday.in).

Salim, S. There is huge problem with the way we are making doctors in this country. Accessed from https://www.youthkiawaaz.com/2015/07/medicaleducation-in-india/

Sood, R. (2008). Medical education in India. Medical Teacher, 30(6), 585-91.

Supe, A., and Burdick, W.P. (2006). Challenges and issues in medical education in India. Academic Medicine, 81(12), 1076-80. 